\title{
MEDIAÇÃO DA INFORMAÇÃO E MEDIAÇÃO PEDAGÓGICA: DISCUSSṌES CONCEITUAIS
}

\author{
MEDIACIÓN DE LA INFORMACIÓN Y LA \\ MEDIACIÓN EDUCATIVA: DISCUSIONES \\ CONCEPTUALES
}

\author{
Helena Célia de Souza Sacerdote* \\ Jorge Henrique Cabral Fernandes ${ }^{\star \star}$
}

\begin{abstract}
RESUMO
Introdução: Trata-se de sistematização de contribuições teóricometodológicas relacionadas aos conceitos de mediação da informação e mediação pedagógica descritos na literatura.

Objetivo: Compreender possível interseção entre a ciência da informação e a educação online no que diz respeito a esses conceitos para verificar se ambos podem ser considerados como análogos em sua essência e práxis.

Metodologia: Revisão bibliográfica baseada na literatura especializada por meio de consulta a produções científicas selecionadas em busca nos bancos de dados do SciELO.ORG e EBSCO Host, no portal de periódicos CAPES/MEC e no Google Acadêmico.

Resultados: Os conceitos mais citados na ciência da informação e na educação foram de Almeida Junior (2009) e de Masetto (2013), respectivamente.

Conclusão: Observa-se que o conceito de mediação pode transitar intercambiavelmente entre ambas as áreas. Isso por que as evidências encontradas nas produções dos últimos cinco anos indicam que o conceito de mediação de informação parece ter encontrado suas bases na área de educação (psicologia educacional).
\end{abstract}

Palavras-chave: Mediação da informação. Mediação pedagógica. Educação online. Ciência da informação.

* Doutoranda no Programa de Pós-Graduação em Ciência da Informação na Universidade de Brasília (UNB). Professora no Centro Universitário de Brasília, (UniCEUB). E-mail: helenasacerdote@gmail.com

** Doutor em Ciência da Computação pela Universidade Federal de Pernambuco (UFPE). Professor na Universidade de Brasília (UNB). E-mail: jhcf@unb.br 


\section{INTRODUÇÃO}

O tema desse estudo é a mediação da informação na sua forma conceitual, que se insere na área de ciência da informação (Cl). No entanto, busca-se entender a relação com o conceito de mediação pedagógica que se insere na área de educação (psicologia educacional).

As características gerais da $\mathrm{Cl}$ são: a sua natureza interdisciplinar; a sua ligação inexorável à tecnologia da informação e sua participação ativa e deliberada na evolução da sociedade da informação (SARACEVIC, 1996). Desse modo, entende-se que tais características se aplicam também à educação, especialmente à educação online. Isto porque a modalidade exige de todos os envolvidos no processo educacional competências em diversas áreas, sendo que uma das primordiais é o uso de tecnologias e de rede de conexão pela internet, sem as quais seria inviável desenvolvê-la.

Filatro (2004) denomina educação online, como a educação que possui características de separação física e temporal, mas tem, obrigatoriamente, conexão com a internet. Essa conexão envolve, não somente o uso das tecnologias, mas também as redes de comunicação interativa e colaborativa para distribuição e promoção de conteúdos educacionais.

A mediação da informação envolve diversos recursos interdisciplinares nas áreas de: informação, comunicação e educação. 0 objetivo dessa interseção é estabelecer estratégias para proporcionar a geração de saberes envolvendo: ambientes, ações, agentes, conteúdos, suportes e recursos tecnológicos (GOMES, 2008).

A mediação da informação é decorrente do processo de interação entre o profissional da informação e o usuário. Essa interação ocorre quando da comunicação e da transferência da informação para que os objetivos entre a necessidade do usuário e a resposta do profissional da informação ocorram. Esse processo dialógico é o elo entre ambos no processo de apropriação da informação (VARELA; BARBOSA, 2007). 
Desse modo, no que diz respeito ao conceito de mediação, adota-se como hipótese que, se as características de origem e evolução da $\mathrm{Cl}$ se assemelham às necessidades estruturais primordiais da educação online, então os conceitos de mediação da informação e mediação pedagógica podem ser utilizados em sinonímia em ambas as áreas.

No entanto, de acordo com Crippa e Almeida (2012), o conceito de mediação apresenta desafios consideráveis dos pontos de vista intelectual e político. Esses autores entendem que o conceito tem características contextualizadas e plásticas, o que pode ser considerado como um conceito sem definição consensual e inviável de ser construído devido à amplitude de práxis a qual abarca.

Assim, a mediação, como conceito, se apresenta com indeterminações e desdobramentos (MALLMANN, 2008, p. 77).

Com o objetivo de sistematizar as contribuições teóricometodológicas relacionadas aos conceitos de mediação da informação e mediação pedagógica descritos na literatura busca-se compreender uma possível interseção entre a $\mathrm{Cl}$ e a educação online no que diz respeito a esses conceitos. A pesquisa baseia-se nas seguintes indagações: os conceitos de mediação da informação e mediação pedagógica podem ser considerados como análogos em sua essência e práxis? Caso não sejam, quais são as suas características distintivas?

Com esse estudo, pretende-se contribuir com possíveis aclaramentos de ordem conceitual em pesquisas em educação e tecnologias e de $\mathrm{Cl}$, que envolvem a mediação para a apropriação da informação e do conhecimento. Trata-se de uma revisão bibliográfica baseada na literatura especializada por meio de consulta a produções científicas selecionadas em busca nos bancos de dados.

\section{METODOLOGIA}

De acordo com Leite (2008), a pesquisa bibliográfica é caracterizada pela análise e interpretação de dados e informações 
colhidas em obras existentes se constituindo em um novo trabalho científico.

As classificações desse trabalho de revisão, de acordo com Moreira (2004), são descritas a seguir.

Essa revisão é do tipo expositivo, pois, pretende expor a análise dos conceitos de mediação de informação e mediação pedagógica a partir da análise e síntese de várias pesquisas.

Quanto ao propósito é considerada uma revisão de base, pois, se constitui em apoio ao referencial teórico de uma tese em andamento inserida no Programa de Pós-graduação em Ciência da Informação (PPGCINF) da Universidade de Brasília (UnB) cujo tema envolve a mediação da informação para apropriação da informação e do conhecimento em educação online.

Quanto à abrangência é considerada temática, pois, se trata de um recorte específico do tema mediação da informação.

Quanto a sua função é considerado uma atualização, pois, destaca os trabalhos mais significativos a respeito do assunto.

Finalmente, quanto ao tratamento e abordagem dos dados analisados, é classificado como bibliográfica, pois, baseia-se em consulta a produções científicas selecionadas em busca em bancos de dados especializados.

Portanto, trata-se de uma revisão bibliográfica baseada na literatura especializada por meio de consulta a produções científicas selecionadas em busca nos bancos de dados do EBSCO Host ${ }^{1}$; no portal de periódicos CAPES/MEC2; SciELO.ORG ${ }^{3}$ e no Google Acadêmico ${ }^{4}$. As produções encontradas estão descritas no Quadro 1.

No portal de periódicos CAPES/MEC, quando da busca por bases em: "Áreas do Conhecimento=Ciências Sociais Aplicadas,

\footnotetext{
1 http://search.ebscohost.com

2 http://periodicos.capes.gov.br

3 http://www.scielo.org

4 http://scholar.google.com.br
} 
Subcategoria=Ciência da Informação" o sistema retornou: Programa de Publicações Digitais da Propg (Unesp); Repositório Científico de Acesso Aberto de Portugal (RCAAP); SciELO.ORG e Repositório Institucional do Museu Paraense Emílio Goeld. Considerando que apenas a base SciELO.ORG recuperou produções com os descritores desejados, optou-se pela busca por assunto.

No portal EBSCO Host, entre as diversas bases de dados por áreas específicas, optou-se pelas: Academic Search Complete e Education Research Complete. Esse banco de dados é acessado por meio de autenticação.

As buscas foram realizadas entre os meses de outubro e novembro de 2014. As palavras-chaves ou descritores utilizados para a busca de produções acadêmicas, no título das obras, foram: "mediação da informação" e "mediação pedagógica".

Foram selecionadas 12 produções acadêmicas, seis de cada área dessa pesquisa. Os critérios utilizados para essa seleção foram por ordem de relevância e cronológica, englobando os últimos cinco anos.

Considerando que a definição mais utilizada de mediação da informação em Cl, de acordo com o Google Acadêmico, é aquela proposta por Almeida Junior (2008) na versão impressa e, o artigo online de Almeida Junior (2009) mantém a mesma definição, considerou-se apenas a sua produção de 2009.

Considerando que a definição mais utilizada de mediação pedagógica, de acordo com o Google Acadêmico, é aquela proposta por Masetto (2013) na versão impressa em sua $20^{\underline{a}}$ edição, também foi incluída nessa seleção.

Para ambos os termos pesquisados, os bancos de dados recuperaram os resultados que constam no Quadro 1. Devido à elevada quantidade de resultados, optou-se por escolher as produções que abordam os temas mais ligados às áreas investigadas nesse trabalho. Desse modo, desconsideraram-se as produções dos bancos de dados SciELO.ORG e EBSCO Host. 
Quadro 1 - resultados quantitativos das buscas nos bancos de dados

\begin{tabular}{|l|c|c|}
\hline \multicolumn{1}{|c|}{ FONTE } & $\begin{array}{c}\text { MEDIAÇÃO DA } \\
\text { INFORMAÇÃO }\end{array}$ & $\begin{array}{c}\text { MEDIAÇÃO } \\
\text { PEDAGÓGICA }\end{array}$ \\
\hline SciELO.ORG & 3 & 55 \\
\hline EBSCO Host periódicos & 31 & 61 \\
\hline $\begin{array}{l}\text { Portal de } \\
\text { CAPES/MEC }\end{array}$ & 1010 & 8080 \\
\hline Google Acadêmico & 1044 & 8161 \\
\hline Total & & \\
\hline
\end{tabular}

Fonte: A autora.

As produções selecionadas foram escritas nos idiomas português e inglês. A análise das produções visou encontrar as definições dos conceitos de mediação da informação e mediação pedagógica em produções tanto em $\mathrm{Cl}$ como aquelas da educação e compará-las para verificar se são compatíveis, podendo ser utilizadas em sinonímia em ambas as áreas.

\section{RESULTADOS}

$\mathrm{Na}$ definição de $\mathrm{Cl}$ proposta por Zins (2007), encontramos a mediação da informação como um aspecto essencial para a área: a Cl é uma área do conhecimento que explora as perspectivas da mediação do conhecimento humano universal. Almeida Junior (2009) também considera que o objeto da $\mathrm{Cl}$ é a mediação da informação.

De acordo com Zins (2007), as perspectivas de mediação incluem aspectos cognitivos, sociais e tecnológicos e condições que facilitam a disseminação do conhecimento humano da fonte para o usuário. A Cl pesquisa como o usuário busca, recupera, dissemina e usa a informação e; a ciência cognitiva pesquisa como o indivíduo entende, lembra e utiliza essa informação. A cognição abrange atividades cerebrais ligadas à atenção, à codificação e à planificação com as quais o ser humano aprende e, a educação está entre as áreas que estudam o cérebro e as suas implicações na aprendizagem, a psicologia educacional. 
A educação online, entendida nesse trabalho em consonância com a definição de Filatro (2004), prevê a figura do tutor ou professor que promove a mediação pedagógica entre os estudantes nos Ambientes Virtuais de Aprendizagem (AVA). Entende-se que o AVA em Educação online se constitui um espaço de mediação pedagógica para apropriação da informação e do conhecimento por meio da interação e colaboração (SACERDOTE, 2013).

O conceito de mediação pedagógica, de acordo com Gutierrez e Prieto (1994, p. 62) é "o tratamento de conteúdos e das formas de expressão dos diferentes temas, a fim de tornar possível o ato educativo dentro do horizonte de uma educação concebida como participação, criatividade, expressividade e relacionalidade.". Apesar de esse conceito ter sido produzido na década de 90, é o segundo mais citado no Google Acadêmico, sendo ultrapassado apenas pelo conceito de Masetto (2013) que, apesar de existirem edições modernas da sua obra na versão impressa, mantém a mesma definição conceitual para a mediação pedagógica, desde a edição original datada do ano 2000.

O conceito de mediação pedagógica de Gutierrez e Pietro (1994) não figura na lista dos conceitos analisados, pois, o contexto dessa pesquisa se insere na educação online, uma modalidade de educação recente, então se infere que os conceitos mais modernos são os mais adequados a essa pesquisa.

A seguir, nos Quadro 2 e Quadro 3, são descritos as informações encontradas na pesquisa, separados por área e em ordem cronológica.

Quadro 2 - descrição das produções acadêmicas selecionadas referentes à $\mathrm{Cl}$

\begin{tabular}{|l|l|l|l|}
\hline \multicolumn{1}{|c|}{ Título } & \multicolumn{1}{|c|}{ Autores } & \multicolumn{1}{c|}{ Fonte } \\
\hline 1 & $\begin{array}{l}\text { Construção e Acionamento } \\
\text { de um Modelo de Mediação } \\
\text { da Informação }\end{array}$ & $\begin{array}{l}\text { FARIAS; VARELA; } \\
\text { FREIRE (2013) }\end{array}$ & $\begin{array}{l}\text { Portal de } \\
\text { periódicos } \\
\text { CAPES/MEC }\end{array}$ \\
\hline 2 & $\begin{array}{l}\text { A mediação da informação } \\
\text { através da comunidade } \\
\text { virtual Anobii: um estudo de } \\
\text { caso }\end{array}$ & $\begin{array}{l}\text { CRIPPA; CARVALHO } \\
(2012)\end{array}$ & $\begin{array}{l}\text { Portal de } \\
\text { periódicos } \\
\text { CAPES/MEC }\end{array}$ \\
\hline
\end{tabular}


Helena Célia de Souza Sacerdote, Jorge Henrique Cabral Fernandes Mediação da informação e mediação pedagógica: discussões conceituais

\begin{tabular}{|l|l|l|l|}
3 & $\begin{array}{l}\text { Information Management } \\
\text { and Mediation in a Digital } \\
\text { Reference Service Focused } \\
\text { in Social Sciences }\end{array}$ & CORDA (2012) & $\begin{array}{l}\text { Portal de } \\
\text { periódicos } \\
\text { CAPES/MEC }\end{array}$ \\
\hline 4 & $\begin{array}{l}\text { Um Estudo da Mediação da } \\
\text { Informação na Produção } \\
\text { Científica da Pós- } \\
\text { Graduação em Educação } \\
\text { da UNESP/Campus de } \\
\text { Marília: Análise das } \\
\text { Citações e Cocitações }\end{array}$ & CUSTÓDIO (2012) & $\begin{array}{l}\text { Portal de } \\
\text { periódicos } \\
\text { CAPES/MEC }\end{array}$ \\
\hline 5 & $\begin{array}{l}\text { Contribuições de } \\
\text { Elementos do } \\
\text { Construtivismo e da } \\
\text { Mediação da Informação } \\
\text { para a Inclusão Digital de } \\
\text { Idosos }\end{array}$ & $\begin{array}{l}\text { VECHIATO; VIDOTTI } \\
(2010)\end{array}$ & $\begin{array}{l}\text { Portal de } \\
\text { periódicos } \\
\text { CAPES/MEC }\end{array}$ \\
\hline 6 & $\begin{array}{l}\text { Mediação da Informação e } \\
\text { Múltiplas Linguagens }\end{array}$ & ALMEIDA JUNIOR (2009) & $\begin{array}{l}\text { Google } \\
\text { Acadêmico }\end{array}$ \\
\hline
\end{tabular}

Fonte: A autora.

Quadro 3 - Descrição produções acadêmicas selecionadas referentes à educação

\begin{tabular}{|l|l|l|l|}
\hline 1 & \multicolumn{1}{|c|}{ Título } & \multicolumn{1}{c|}{ Autores } & \multicolumn{1}{c|}{ Fonte } \\
\hline 1 & $\begin{array}{l}\text { Mediação e Interação na } \\
\text { Educação a Distância: } \\
\text { Relação Professor e Aluno }\end{array}$ & LOZANO et al. (2014) & Google Acadêmico \\
\hline 2 & $\begin{array}{l}\text { Novas Tecnologias e } \\
\text { Mediação Pedagógica }\end{array}$ & MASETTO (2013) & $\begin{array}{l}\text { Google Acadêmico } \\
\text {-Livro impresso }\end{array}$ \\
\hline 3 & $\begin{array}{l}\text { Mediação Pedagógica } \\
\text { online: análise das funções } \\
\text { do tutor na Universidade } \\
\text { Aberta do Brasil }\end{array}$ & AMARO (2012) & $\begin{array}{l}\text { Portal de } \\
\text { periódicos } \\
\text { CAPES/MEC }\end{array}$ \\
\hline 4 & $\begin{array}{l}\text { Mediação pedagógica o } \\
\text { sucesso de uma experiência } \\
\text { educacional online }\end{array}$ & SCHNITMAN (2011) & $\begin{array}{l}\text { Portal de } \\
\text { periódicos } \\
\text { CAPES/MEC }\end{array}$ \\
\hline 5 & $\begin{array}{l}\text { Mediação computacional } \\
\text { como fator de motivação e } \\
\text { de aprendizagem } \\
\text { significativa no ensino de } \\
\text { ciências do 9o ano: tópico de } \\
\text { astronomia }\end{array}$ & SILVA (2010) & $\begin{array}{l}\text { Portal de } \\
\text { periódicos } \\
\text { CAPES/MEC }\end{array}$ \\
\hline $\begin{array}{l}\text { A disciplina Sociologia no } \\
\text { ensino médio: perspectivas } \\
\text { de mediação pedagógica e } \\
\text { tecnológica. Um diálogo } \\
\text { possível }\end{array}$ & LEODORO (2009) & $\begin{array}{l}\text { Portal de } \\
\text { periódicos } \\
\text { CAPES/MEC }\end{array}$ \\
\hline
\end{tabular}

Fonte: A autora. 


\subsection{Conceitos de Mediação da Informação}

Farias, Varela e Freire (2013, p. 176) citam Almeida Júnior (2008), e definem mediação da informação como uma "ação vinculada à vida, ao movimento, ao processo de construção de sentidos na realidade histórico-social de cada indivíduo" e que ocorre a partir do desenvolvimento do ser humano pela interação social.

Crippa e Carvalho (2012), apesar de não apresentarem uma definição de mediação da informação, citam as definições conceituais de Almeida Junior (2009) e Almeida Junior (2008). A mediação é identificada em uma comunidade virtual de leitores, onde existe a possibilidade de cada leitor expressar a sua opinião acerca dos livros lidos e dos comentários de outros leitores, exercitando a crítica e o debate entre os usuários. Nesse contexto, o leitor assume os papéis de autor, crítico e bibliotecário de referência.

Corda (2012) cita o conceito de mediação literalmente de acordo com Almeida Junior (2009). A autora também cita Almeida Junior (2008) e completa que a mediação baseada na interferência é oposta à ideia de isolamento ou passividade. Toda a informação social, de alguma maneira, influencia, demanda atitudes e mudanças no espaço informacional naqueles que nela trabalham.

Custódio (2012) também aborda a definição de mediação da informação de Almeida Junior (2009). Essa autora entende que questões relacionadas à aprendizagem e ao desenvolvimento são estudos interdisciplinares e envolvem as áreas de $\mathrm{Cl}$ e a educação. $\mathrm{A}$ mediação torna possível a aprendizagem e a produção e construção do conhecimento por meio da interação e da participação dialógica do processo de ensino e aprendizagem.

Vechiato e Vidotti (2010) citam a definição de Almeida Júnior (2008) para a mediação da informação e entendem a mediação como a identificação das habilidades, potencialidades e experiências dos idosos, como ponto de partida para que o professor, no papel de mediador, 
trace e elabore o plano de ensino adequado para a capacitação desses indivíduos.

Almeida Junior (2009) define a mediação da informação como todas as formas de ações de interferência realizadas pelos profissionais da informação visando a apropriação de informação para satisfazer a necessidade informacional do usuário. Apesar de esse conceito ter sido definido na sua obra de 2008 na versão impressa, o autor inclui os conceitos de mediação implícita e explícita. A mediação implícita compreende as ações desenvolvidas de forma consciente pelo indivíduo baseada nos conhecimentos que se domina e exterioriza com algum controle. A mediação explícita abrange as ações que transparecem um conhecimento inconsciente, da qual não há controle e que se sobrepõe aos conhecimentos conscientes. O autor defende a ideia de não neutralidade do mediador bem como do processo de mediação, pois, abarcam os conhecimentos conscientes e inconscientes dos indivíduos envolvidos no processo.

\subsection{Conceitos de Mediação Pedagógica}

Lozano et al. (2014) citam Masetto (2000) enfatizando que a mediação pedagógica é o comportamento do professor como papel principal, incentivador da aprendizagem, agindo como um elo entre o estudante e o conhecimento, valorizando o diálogo na troca de experiências entre os participantes do processo, por meio do debate e da interação.

Para Masetto (2013), a mediação pedagógica envolve a interação, ou as relações, entre professor e estudante, entre estudante e estudante, entre estudante e conteúdo e até o estudante consigo mesmo. Envolvem diálogos, as trocas de experiências, debates para resolver dúvidas e problemas, reflexões, o estabelecimento de conexões entre o conhecimento e novos conceitos, o desenvolvimento do senso crítico, ético e colaborativo. Entre as características do professor mediador estão, o planejamento e as ações da aprendizagem centrados 
no estudante, a parceria e a corresponsabilidade no processo, a criatividade, o diálogo, entre outros, vez que ambos (professor e estudante) constituem-se a célula básica do desenvolvimento da aprendizagem.

Schnitman (2011) também cita Masetto (2000) abordando as características da mediação pedagógica que compreende diálogos, trocas de experiências, debates, abordagem de problemas, perguntas orientadoras propondo desafios, incentivando a reflexão, criando intercâmbios entre a aprendizagem e a realidade social e, ainda, a aprendizagem de comunicação de conhecimentos por meio da colaboração. A autora entende que a mediação pedagógica em educação online pressupõe que a interação do professor promova uma aprendizagem mais atraente e colaborativa de forma que o estudante alcance o seu objetivo educacional.

Silva (2010) cita Masetto (2010) e acrescenta que, na mediação pedagógica, o professor assume o papel de parceiro criativo e articulador da aprendizagem junto ao estudante, sugerindo caminhos e direcionando os processos que facilitem a aprendizagem.

Amaro (2012) cita Masetto (2009) enfatizando o papel do professor como facilitador, incentivador ou motivador da aprendizagem apoiando o aprendiz no processo de ensino e aprendizagem como uma ponte dinâmica para atender aos objetivos educacionais do estudante. $A$ autora entende que a mediação pedagógica está ligada ao conceito de interação e este à interatividade em uma conversão e complementação envolvendo o professor e o estudante.

Leodoro (2009) cita Masetto (2000) e define que a mediação pedagógica pressupõe relação humanizante que extrapola a transmissão de conteúdos por meio de aulas expositivas e avaliação individual para verificar a retenção e assimilação do conteúdo. 


\section{DISCUSSÃO}

Podemos perceber que Zins (2007) indica a existência de uma relação entre as áreas de $\mathrm{Cl}$ e de aprendizagem humana, embora ambas possuam focos distintos.

Todas as produções selecionadas referentes à mediação da informação (ver Quadro 2) citaram a definição conceitual de Almeida Junior (2009) e/ou Almeida Junior (2008). Desse modo, a definição consensual para mediação da informação, baseada na literatura é:

Toda ação de interferência - realizada pelo profissional da informação -, direta ou indireta; consciente ou inconsciente; singular ou plural; individual ou coletiva; que propicia a apropriação de informação que satisfaça, plena ou parcialmente, uma necessidade informacional (ALMEIDA JUNIOR, 2009, p. 92).

De acordo com Almeida Júnior (2009), o emprego de alguns sinônimos, tais como "ponte" para o "mediador" e "cliente" para o "usuário", não é apropriado. Isso porque esses termos remetem à ideia de estática e passividade, enquanto que o processo de mediação é dinâmico e envolve a participação ativa dos envolvidos. Para esse autor, o usuário é um ser ativo, participativo e decisivo, que interfere nos significados da informação. O conhecimento só acontece por meio da interação do usuário com o mundo que se coloca como ator central no processo de apropriação. Esse usuário se torna construtor, coprodutor da informação em oposto à figura de um mero receptor. A autoria passa a ser distribuída entre todos os potenciais usuários da informação.

Almeida Júnior (2009) enfatiza que, a informação deve ser mediada e não meramente disseminada ou transferida. Para o autor, os profissionais da informação medeiam ou, atuam como mediadores, interferindo de maneira contundente em todo o processo da apropriação da informação pelo usuário.

Todas as produções selecionadas referentes à mediação pedagógica (ver Quadro 3) citaram a definição conceitual de Masetto 
(2009) ou outras edições de sua obra impressa. Desse modo, as definições consensuais para mediação pedagógica, baseada na literatura são:

\begin{abstract}
A atitude, o comportamento do professor que se coloca como um facilitador, um incentivador ou motivador da aprendizagem, que se apresenta com a disposição de ser uma ponte entre o aprendiz e sua aprendizagem não uma ponte estática, mas uma ponte "rolante", que ativamente colaborado para que o aprendiz chegue aos seus objetivos. É a forma de se apresentar e tratar um conteúdo ou tema que ajuda o aprendiz a coletar informações, relacioná-las, organizá-las, manipulá-las, discuti-las e debatê-las com seus colegas, com o professor e com outras pessoas (interaprendizagem), até chegar a produzir um conhecimento que seja significativo para ele, conhecimento que se incorpore ao seu mundo intelectual e vivencial, e que o ajude a compreender sua realidade humana e social, e mesmo a interferir nela (MASETTO, 2013, p. 144-145).
\end{abstract}

Entre as 12 produções selecionadas, seis delas citaram os teóricos da área de educação referentes à mediação: Vygotsky (ALMEIDA JUNIOR, 2008, 2009; CUSTÓDIO, 2012; FARIAS; VARELA; FREIRE, 2013; LEODORO, 2009; SCHNITMAN, 2011;) e Paulo Freire (ALMEIDA JUNIOR, 2008, 2009; CUSTÓDIO, 2012; LEODORO, 2009; SCHNITMAN, 2011; VECHIATO; VIDOTTI. 2010;). No que diz respeito às áreas, houve mais citações desses teóricos por parte dos autores de $\mathrm{Cl}$, sendo quatro produções contra duas produções da educação. Considerando que o presente artigo foca na literatura mais recente, desconsideraram-se as obras dos autores Vygotsky e Paulo Freire.

É relevante aludir que Almeida Junior (2009) argumenta que o sociointeracionismo - que compreende a construção do conhecimento baseada na interação entre sujeitos e com o mundo -, baseado nas teorias de Vigotsky e de Paulo Freire, contribui fundamentalmente para as reflexões acerca da mediação da informação. Desse modo, se infere que a $\mathrm{Cl}$ se baseia em teorias da área de educação (psicologia educacional) no que diz respeito à mediação. 
Masetto (2013) e Almeida Junior (2009) reconhecem a figura de um mediador que intervém de maneira dinâmica entre o usuário e a informação visando a satisfação de uma necessidade informacional. Embora Almeida Junior (2009) rechace a ideia de ponte para a figura do mediador pela noção de passividade que ela traduz, Masetto (2013) inteira que quando utiliza a figura da ponte se refere a uma ponte rolante que proporciona colaboração ativa entre os participantes do processo de ensino e aprendizagem. Também Amaro (2012) se refere à mediação como ponte dinâmica para o atendimento dos objetivos educacionais.

Quando Masetto (2013) se refere à práxis da mediação pedagógica, há semelhança com a definição de sistemas de informação em $\mathrm{Cl}$, quando se propõe a ajudar o aprendiz a coletar informações, relacioná-las, organizá-las, manipulá-las, discuti-las e debatê-las com outras pessoas para a apropriação do conhecimento de maneira que isso permita que o indivíduo interfira na sua realidade. Dessa forma, o aprendiz pode se tornar coautor ou coprodutor da informação, o que está em consonância com a posição de Almeida Junior (2009).

Sistema de Informação é o conjunto de meios humanos, tecnológicos, de dados e procedimentos inter-relacionados que coletam, processam, armazenam e distribuem informações com o objetivo de apoiar a tomada de decisões, a coordenação e o controle de uma organização (SOUSA, 2008).

Ainda Custódio (2012), oriunda da $\mathrm{Cl}$, sugere que por meio da mediação, a aprendizagem e o desenvolvimento da produção e da construção do conhecimento transcorrem por meio da interação e participação dialógica tanto da parte de quem ensina quanto de quem aprende.

Considerando a limitação das bases pesquisadas, entende-se que, a mediação pedagógica, tal como a mediação da informação, pode ser considerada como o relacionamento entre a informação, o mediador e o usuário, sendo esses participantes ativos e colaborativos no processo de construção de novos saberes. Desse modo, em um ambiente de interação, tal como na educação online, o papel da 
mediação favorece um contexto dialógico, reflexivo, construtivo e colaborativo.

\section{CONCLUSÃO}

Sendo o objetivo desse estudo, descrever e analisar os conceitos de mediação da informação e mediação pedagógica descritos na literatura para verificar se ambos podem ser considerados como análogos em sua essência e práxis, observou-se que o conceito de mediação pode transitar intercambiavelmente entre ambas as áreas estudadas: Cl e educação. Isso por que as evidências encontradas nas produções dos últimos cinco anos indicam que o conceito de mediação de informação parece ter encontrado suas bases na educação (psicologia educacional) o que confirma a hipótese adotada nesse trabalho.

As limitações encontradas foram o número elevado de produções retornadas pelas principais bases escolhidas para esse estudo. Desse modo, foi essencial filtrar as produções pelas áreas de publicação estudadas.

Assim, um aprofundamento dessa pesquisa utilizando fontes de informações em outras áreas correlatas à $\mathrm{Cl}$ e à educação para verificar outras intersecções indica ser oportuno em estudos futuros.

\section{REFERÊNCIAS}

ALMEIDA JUNIOR, Oswaldo Francisco. Mediação da informação e múltiplas linguagens. Tendências da pesquisa brasileira em ciência da informação, João Pessoa, v. 1, n. 2, p. 89-103, dez. 2009. Disponível em: <http://inseer.ibict.br/ancib/ index.php/tpbci/article/viewArticle/17>. Acesso em: 27 out. 2014.

ALMEIDA JUNIOR, Oswaldo Francisco. Mediação da informação: ampliando o conceito de disseminação. In: VALENTIM, Marta Lígia Pomim. Gestão da informação e do conhecimento. São Paulo: Polis, 2008. p. 41-54. 
AMARO, Rosana. Mediação pedagógica online: análise das funções do tutor na Universidade Aberta do Brasil. 2012. 85 f. Dissertação (Mestrado em Educação) - Universidade de Brasília, Brasília, 2012.

CORDA, Maria Cecilia. Information management and mediation in a digital reference service focused in social sciences. Brazilian Journal Of Information Science, Marilia, v. 2, n. 6, p. 89-104, dez. 2012. Disponível em: <http://www2.marilia.unesp.br/revistas/index.php/bjis/article/view/2756>. Acesso em: 3 nov. 2014.

CRIPPA, Giulia; CARVALHO, Larissa Akabochi. A mediação da informação através da comunidade virtual Anobii: um estudo de caso. Encontros Bibli: Revista Eletrônica de Biblioteconomia e Ciência da Informação, Florianópolis, v. 35, n. 17, p. 97-120, 2012. Disponível em: $<$ https://periodicos.ufsc.br/index.php/ eb/article/view/15182924.2012v17n35p97/23584>. Acesso em: 1 nov. 2014.

CUSTÓDIO, Pollyana Ágata Gomes da Rocha. Um estudo da mediação da informação na produção científica da pós-graduação em educação da UNESP/Campus de Marília: análise das citações e cocitações.

Nuances: Estudos sobre Educação, Presidente Prudente, v. 24, n. 23, p. 202-225, jan. 2012. Disponível em:

$<$ http://revista.fct.unesp.br/index.php/Nuances/article/view/1898/Pollyana >. Acesso em: 2 nov. 2014.

FARIAS, Maria Giovanna Guedes; VARELA, Aida Varela; FREIRE, Isa Maria. Construção e acionamento de um modelo de mediação da informação. Informação e Sociedade: Estudos, João Pessoa, v. 3, n. 23, p. 175-188, set. 2013. Disponível em:

<http://www.ies.ufpb.br/ojs2/index.php/ies/article/view/17315/10214>. Acesso em: 3 nov. 2014.

FILATRO, Andrea. Design instrucional contextualizado: educação e tecnologia. São Paulo: SENAC, 2004.

GOMES, Henriette F. A mediação da informação, comunicação e educação na construção do conhecimento. DataGramaZero: Revista de Ciência da Informação, Rio de Janeiro, v. 9, n. 1, fev. 2008. Disponível em: <http://www.dgz.org.br/ fev08/Art_01.htm>. Acesso em: 5 jan. 2016.

GUTIERREZ, Francisco; PIETRO, Daniel. A mediação pedagógica: educação a distância alternativa. São Paulo: Papirus, 1994.

LEITE, Francisco Tarciso. Metodologia científica: métodos e técnicas de pesquisa (Monografias, Dissertações, Teses e Livros). Aparecida (S.P.): Ideias \& Letras, 2008. 
LEODORO, Silvana Aparecida Pires. A disciplina sociologia no ensino médio: perspectivas de mediação pedagógica e tecnológica. Um diálogo possível. 2009. 252 f. Dissertação (Mestrado em Educação) Faculdade de Educação, Universidade de São Paulo, São Paulo, 2009. Disponível em: <http://www.teses.usp.br/teses/ disponiveis/48/48134/tde-29032010-141607/pt-br.php>. Acesso em: 12 nov. 2014.

LOZANO, Taissa Vieira et al. Mediação e interação na educação a distância: relação professor e aluno. In: SIMPÓSIO INTERNACIONAL DE EDUCAÇÃ̃ A DISTÂNCIA, 1., 2014, São Carlos. Anais... São Carlos: SIED, 2014. p. 1-13. Disponível em: <http://www.siedenped2014.ead.ufscar.br/ojs/index.php/2014/article/view/670/385>. Acesso em: 8 nov. 2014.

MALLMANN, Elena Maria. Mediação pedagógica em educação a distância: cartografia da performance docente no processo de elaboração de materiais didáticos. 2008. 304 f. Tese (Doutorado em Educação) - Universidade Federal de Santa Catarina, Florianópolis, 2008. Disponível em: <https://repositorio.ufsc.br /xmlui/bitstream/handle/123456789/91842/250559.pdf?sequence=1\&isAl lowed=y>. Acesso em: 12 jul. 2014.

MASETTO, Marcos T. Mediação pedagógica e o uso da tecnologia. In: MORAN, José Manuel (Org.). Novas tecnologias e mediação pedagógica. 20. ed. Campinas: Papirus, 2013. p. 133-179.

MOREIRA, Walter. Revisão de literatura e desenvolvimento científico: conceitos e estratégias para confecção. Janus, Lorena, v. 1, n. 1, p. 130, out. 2004. Disponível em:

<http://www.publicacoes.fatea.br/index.php/janus/article/viewArticle/1>. Acesso em: 26 out. 2014.

SACERDOTE, Helena Célia de Souza. Análise da mediação em educação online sob a ótica da análise de redes sociais: o caso do curso de especialização em gestão da segurança da informação e comunicações. 2013. 145 f. Dissertação (Mestrado em Ciência da Informação) - Universidade de Brasília, Brasília, 2013.

SARACEVIC, Tefko. Ciência da informação: origem, evolução e relações. Perspectivas em Ciência da Informação, Belo Horizonte, v. 1, n. 1, p. 41-62, jan./jun. 1996. Disponível em:

<http://portaldeperiodicos.eci.ufmg.br/index.php/pci/ article/view/235/22>. Acesso em: 20 out. 2014.

SCHNITMAN, Ivana Maria. A mediação pedagógica e o sucesso de uma experiência educacional on-line. Educação Temática Digital, Campinas, v. 12, n. esp., p. 287-314, nov. 2011. Disponível em: <http://www.fe.unicamp.br/revistas/ged/etd/article/view/2263/pdf_61>. Acesso em: 7 nov. 2014. 
SILVA, Fernando Marcos da. Mediação computacional como fator de motivação e de aprendizagem significativa no ensino de ciências do 9ano: tópicos de astronomia. 2010. 96 f. Dissertação (Mestrado em Educação em Ciências e Matemática) - Universidade Federal de Goiás, Goiânia, 2010. Disponível em:

<https://mestrado.prpg.ufg.br/up/97/o/Diss_047.pdf>. Acesso em: 24 out. 2014.

SOUSA, Beatriz A. Glossário: biblioteconomia - arquivologia comunicação e ciência da informação. 2. ed. João Pessoa: Editora Universitária/UFPB, 2008.

VARELA, Aida; BARBOSA, Marilene L. A. Aplicação de teorias cognitivas no tratamento da informação. Revista Brasileira de

Biblioteconomia e Documentação: Nova Série, São Paulo, v. 3, n. 2, p. 116-128, jul./dez. 2007. Disponível em:

<http://www.febab.org.br/rbbd/index.php/rbbd/article/view/65/56>.

Acesso em: 4 dez. 2011.

VECHIATO, Fernando Luiz; VIDOTTI, Silvana Aparecida Borsetti Gregorio. Contribuições de elementos do construtivismo e da mediação da informação para a inclusão digital de idosos. Informação \& Informação, Londrina, v. 2, n. 15, p. 40-59, dez. 2010. Disponível em: $<$ http://www.uel.br/revistas/uel/index.php/informacao/ article/view/6623/6997>. Acesso em: 8 nov. 2014.

ZINS, Chaim. Conceptions of information science. Journal of the American Society for Information Science and Technology, New York, v. 58, n. 3, p. 335-350, 2007. Disponível em: <http://www.success.co.il/is/zins_conceptsof_is.pdf>. Acesso em: 15 out. 2014.

Title

Mediation of information and educational mediation: conceptual discussions

\begin{abstract}
Introduction: This is systematization of theoretical and methodological contributions related to the concepts of mediation information and pedagogical mediation in the literature.

Objective: To understand possible intersection of information science and Online Education with regard to these concepts to check that both can be considered as analogous in its essence and practice.

Methodology: Literature review based on literature by consulting the scientific productions selected in search of SciELO.ORG databases and EBSCO Host, the portal of CAPES / MEC and Google Scholar.
\end{abstract}


Results: The most cited concepts in information science and education were de Almeida Junior (2009) and Masetto (2013), respectively.

Conclusion: It is observed that the concept of mediation can move interchangeably between both areas. This is because the evidence found in the productions of the last five years indicate that the concept of information of mediation seems to have found its bases in education (educational psychology).

Keywords: Information mediation. Educational mediation. Online education. Information science.

\section{Titulo}

Mediación de la información y la mediación educativa: discusiones conceptuales

\section{Resumen}

Introducción: Esta es la sistematización de los aportes teóricos y metodológicos relacionados con los conceptos de mediación de información y mediación mediación pedagógica en la literatura.

Objetivo: Comprender posible intersección de ciencias de la información y la educación en línea con respecto a estos conceptos para verificar que ambas pueden considerarse como análoga en su esencia y práctica.

Metodología: Revisión de la literatura basada en la literatura mediante la consulta de las producciones científicas seleccionadas en la búsqueda de bases de datos SciELO.ORG y EBSCO Host, el portal de la CAPES / MEC y Google Scholar.

Resultados: Los conceptos más citados en ciencias de la información y la educación eran de Almeida Júnior (2009) y Masetto (2013), respectivamente.

Conclusión: Se observa que el concepto de mediación puede moverse indistintamente entre ambas áreas. Esto se debe a la evidencia encontrada en las producciones de los últimos cinco años indican que el concepto de mediación de información parece haber encontrado sus bases en educación (psicología de la educación).

Palabras clave: Mediación de información. La mediación pedagógica. La educación en línea. Ciencia de la información.

Recebido: 05.12.2014

Aceito: 10.02 .2016 